\title{
INFORMACIÓN TURÍSTICA DE LA COMUNIDAD PILE, MONTECRISTI, MANABÍ,
} ECUADOR

AUTORES: Juan Francisco Villamar González ${ }^{1}$

Luis David Zambrano Figueroa ${ }^{2}$

Héctor Simón Pinargote Vélez ${ }^{3}$

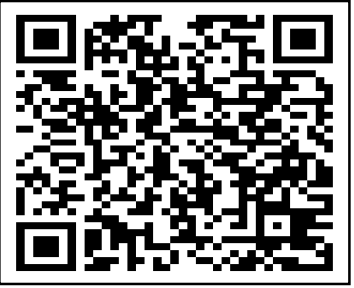

\section{DIRECCIÓN PARA CORRESPONDENCIA: juan.villamar@unesum.edu.ec}

Fecha de recepción: 10/12/2020

Fecha de aceptación: 26/04/2021

\section{RESUMEN}

Una tendencia que se está desarrollando actualmente es investigar antes de viajar, es decir que el turista busca su propia información en diversas páginas de internet y no busca las agencias de viajes tradicionales. Debido a la escaza y desactualizada información turística que existe en Manabí, el objetivo es sistematizar la información turística de la comunidad Pila, que facilitará las decisiones de los encargados de formular políticas y los gerentes del destino, proporcionando información sobre los factores turísticos que se deben actuar para fortalecer. Se realizaron entrevistas, encuestas y recorridos por el área. En el área existen alrededor de 1100 habitantes, distribuidos en más de 80 viviendas. La población no cuenta con todos los servicios básicos. La mayoría de los residentes no tiene estudios, los jóvenes llegan a la primaria y una pequeña parte estudian la secundaria. El modo de vida se basa en la fabricación, tejido y comercio del sombrero fino de paja toquilla. La especie utilizada es Carludovica palmata Ruiz \& Pav. Su potencial turístico se valoró de clase "A", como un área de calidad alta, con rasgos singulares y sobresalientes, además con un mínimo impacto ambiental provocado por los pobladores, los cuales se esfuerzan por preservar el medio que los rodea, es una comunidad que se presta para desarrollar varias actividades y modalidades turísticas.

PALABRAS CLAVE: Sistematización, información turística, paja toquilla, Pile, Manabí.

\section{TOURIST INFORMATION OF THE PILE COMMUNITY, MONTECRISTI, MANABÍ, ECUADOR}

\footnotetext{
${ }^{1}$ Licenciado en Ecoturismo y magister Gestión Internacional de Turismo, Contratado de la Carrera de Turismo, Facultad de Ciencias Económicas en la Universidad Estatal del Sur de Manabí, Jipijapa, Ecuador. Email: juan.villamar@unesum.edu.ec. https://orcid.org/0000-0001-7133-2748

${ }^{2}$ Estudiante de la Carrera de Turismo, Facultad de Ciencias Económicas, Universidad Estatal del Sur de Manabí. Email: davidzambrano98edu.ec@gmail.com. https://orcid.org/0000-0002-8446-9740

3 Licenciado en Administración Turística y Hotelera, Magister en Educación y Desarrollo Social. Docente Contratado de la Carrera de Turismo, Facultad de Ciencias Económica de la Universidad Estatal del Sur de Manabí, Ecuador. Email: hector.pinargote@unesum.edu.ec. https://orcid.org/0000-0001-5914-5720
} 
Juan Francisco Villamar González, Luis David Zambrano Figueroa, Héctor Simón Pinargote Vélez

\begin{abstract}
A trend that is currently developing is to research before traveling, that is, the tourist searches for their own information on various websites and does not search for traditional travel agencies. Due to the scarcity and outdated tourist information that exists in Manabí, the objective is to systematize the tourist information of the Pila community, which will facilitate the decisions of policy makers and destination managers, providing information on the tourist factors that should be act to strengthen. Interviews, surveys and tours of the area were carried out. In the area there are around 1100 inhabitants, distributed in more than 80 houses. The population does not have all the basic services. Most residents have no education, young people go to primary school, and a small part study secondary school. The way of life is based on the manufacture, weaving and trade of the fine toquilla straw hat. The species used is Carludovica palmata Ruiz \& Pav. Its tourist potential was valued as class "A", as a high quality area, with unique and outstanding features, in addition to a minimal environmental impact caused by the inhabitants, who strive to preserve the environment that surrounds them, is a community that lends itself to develop various activities and tourist modalities.
\end{abstract}

KEYWORDS: Systematization, tourist information, toquilla straw, Pile, Manabí.

\title{
INTRODUCCIÓN
}

La revolución científica acaecida en la segunda mitad del siglo XX afectó de manera particular a la realidad informativa y sus diversos dominios. El surgimiento de la Ciencia de la Información fue resultado de la proliferación disciplinaria y la instauración de un paradigma, en concreto el denominado físico. Este paradigma resultó determinante en la creación y consolidación de la integridad y singularidad del nuevo campo del conocimiento, en un período histórico concreto, y definió su independencia y autonomía (Vega-Almeida et al., 2009).

El Análisis Jerárquico Multicriterio es una herramienta que aporta a la toma de decisiones sobre la gestión del territorio, al establecer prioridades para el desarrollo de programas y proyectos que mejoren la calidad de los atractivos turísticos más relevantes, así como su promoción en los segmentos de mercado identificados. Esta metodología plantea la organización del territorio desde la actividad turística a través de la contextualización de tres grupos de criterios: eco-naturales, socioculturales y de gestión del territorio; lo que implica el aumento de la conectividad de las variables complejas del fenómeno turístico (Herrera et al., 2014).

La búsqueda de información turística es un tema complejo (Wee-Kheng y Tong-He, 2012). Investigar los sitios antes de viajar, es una tendencia que se está desarrollando actualmente. El turista busca su propia información sistematizada en diversas páginas de internet. Debido a la escasa y desactualizada información turística sistematizada que existe en el país, esta tarea se hace difícil. Una de las causas por lo cual no existe esta información es por la falta de planificación y sistematización en el desarrollo territorial turístico, trayendo consigo consecuencias como la ausencia de turistas. Es en este sentido, que el presente trabajo, se centra en el caso de estudio Pile, una comunidad de la provincia de Manabí, Ecuador, lugar turístico donde viven los tejedores de sombrero fino de paja toquilla, reconocido por la UNESCO como patrimonio inmaterial de la humanidad (desde el 2012). El objetivo es sistematizar la información turística, que facilitará las decisiones de los encargados de formular políticas y los gerentes del 
destino, proporcionando información sobre los factores turísticos que se deben actuar para fortalecer.

\section{PROBLEMATIZACIÓN}

Los paisajes tienen una posición central en muchos destinos de turismo rural. Proporcionan tanto activos como límites para el desarrollo del turismo, e indirectamente proporcionan el marco en el que el turismo a menudo se considera como una herramienta de desarrollo regional. Sin embargo, la complejidad de las interacciones entre paisajes y turismo ha dado como resultado interpretaciones múltiples y, a veces, contrastantes, y enfoques de investigación relacionados con las interacciones paisaje-turismo (Stoffelen y Dominique, 2015). Los entornos rurales son cada vez más apreciados por el turismo basado en la naturaleza. Para beneficiarse de esto y mantener el atractivo de un destino turístico, es importante reconocer los valores de los paisajes (Scolozzi et al.,2015).

El problema de los recursos de la provincia de Manabí es que no existe una guía sistematizada que brinde información de todos los atractivos, accesibilidad, señaléticas, entre otras. La causa de este problema es la poca información que existe es el internet, dirección de turismo del GAD, ya que no hay información actualizada y sistematizada sobre los recursos y atractivos turísticos de la comunidad "Pile" del cantón Montecristi y además el gobierno municipal no se preocupa por investigar más sobre estos entornos, trayendo como consecuencia un declive de visitantes en las parroquias, por una escaza referencia de datos organizados sobre flora y fauna, etnografía y la actividad económica de esta población; información que no está sistematizada en los “Centros de Información Turísticas”

\section{DESARROLLO}

\section{Descripción del área de estudio}

La comunidad Pile, pertenece al cantón Montecristi, en la provincia de Manabí, Ecuador. Se localiza exactamente a 40 minutos de la ciudad de Montecristi y a 50 minutos de la ciudad de Manta. Existen dos vías para llegar a este lugar: La primera es por la Ruta de la Spondyllus que es una vía de primer orden y permite ver el Océano Pacífico en el trayecto, así como los ceibos que son tradicionales de la vegetación manabita. La segunda es por la vía denominada Los Bajos es la única ruta que toman los buses de transporte público.

En el área existen alrededor de 1100 habitantes, distribuidos en más de 80 viviendas. La población no cuenta con todos los servicios básicos. La mayoría de residentes cuentan con ingresos menores a los $\$ 200$, y pocos son los que cuentan con ayudas sociales, como el bono de desarrollo humano. Tiene luz eléctrica, agua entubada que baja desde los cerros aledaños hasta cada una de las viviendas y alcantarillado sanitario pero la mayor parte de los hogares continúan con la utilización de sus propios pozos sépticos y no se han conectado a la red pública; tampoco tiene conexión telefónica fija o móvil. Las actividades económicas son escasas pues se dedican principalmente a la agricultura y al tejido de sombreros de paja toquilla. Hay quienes han decido trabajar fuera de su comunidad y se emplean en la construcción y a la pesca. 
Juan Francisco Villamar González, Luis David Zambrano Figueroa, Héctor Simón Pinargote Vélez

\section{MÉTODOS}

La investigación se realizó en el periodo noviembre 2019 marzo 2020, donde desarrollamos y probamos una metodología de valoración espacial cualitativa, integrando los métodos de encuestas cuantitativas existentes, para apoyar la gestión de destinos y la planificación del paisaje a nivel local. Los datos se recopilaron mediante entrevistas semiestructuradas y un ejercicio de mapeo en un destino turístico basado en la naturaleza en la comunidad de Pile.

El análisis de la sistematización de la información fue conducido en cuatro fases: revisión bibliográfica, preparación de la encuesta y entrevista, recolección de datos y procesamiento de la información, para ello se emplearon fuentes primarias y secundarias. Se realizaron 30 visitas a la comunidad.

Se realizó entrevistas (Método Delphi) a expertos y se efectuó encuestas a 48 personas relacionadas con varios servicios turísticos, la preparación de la materia prima, tejido del sombrero de paja toquilla, la muestra consideró un nivel de confianza del 95\% y un margen de error del 10\%, la aplicación de la misma se realizó durante una semana.

En la encuesta, realizadas a 832 residentes, se consideraron temas relacionados con los criterios eco-naturales, socioculturales y de gestión del territorio, además se evaluó el potencial ecológico del área con fines turísticos. Para la evaluación y caracterización del paisaje, el método desarrollado incluye las fases propuestas por Méndez-Méndez et al. (2018). Al consolidar la información antes mencionada, se identificó el potencial turístico, aspectos de la cultura, formas de vida y economía de la comunidad. Se realizó una encuesta independiente dirigida al presidente de la comunidad y/o el antropólogo encargado del Instituto Nacional de Patrimonio Cultural (INPC), con el fin de conocer los sitios donde se elabora la artesanía del sombrero de paja toquilla, número de tejedores activo, y donde se colecta la especie.

\section{Resultados y discusión}

En base a la observación de campo, se obtuvo que en la comunidad de Pile, no existen parques. La iglesia se encuentra en buenas condiciones y está ubicada en la zona centro. Existe un "Subcentro de salud" y se encuentra cerca de la escuela. La escuela se encuentra en un buen estado y está ubicada cerca de la zona céntrica. Hay un cementerio público que no se encuentra en muy buenas condiciones y está un poco alejado de la zona céntrica. Las calles de Piles son de tierra y para obtener señal de celular en el centro urbano hay que acercarse a la puerta de la iglesia, templo al que asiste dos veces por mes el sacerdote desde la comunidad vecina de San Mateo a dar la misa.

Las entrevistas revelaron que la mayoría de los residentes no tiene estudios, los jóvenes llegan a la primaria y una pequeña parte estudian la secundaria, las encuestas revelaron que es casi inexistente la educación de tercer nivel. En la mayoría de los casos las personas cuentan con capital propio para realizar sus actividades, sin embargo, existen quienes reciben ingresos de familiares u otras fuentes.

El análisis de las encuestas evidenció la siguiente información: 
Tabla 1.- ¿Cuántas personas habitan en la casa?

\begin{tabular}{|l|l|l|}
\hline ALTERNATIVAS & FRECUENCIA & PORCENTAJE \\
\hline $\mathbf{1 - 5}$ & 41 & $68 \%$ \\
\hline $\mathbf{1 - 7}$ & 12 & $20 \%$ \\
\hline 9 o más & 7 & $11 \%$ \\
\hline TOTAL & 60 & $100 \%$ \\
\hline
\end{tabular}

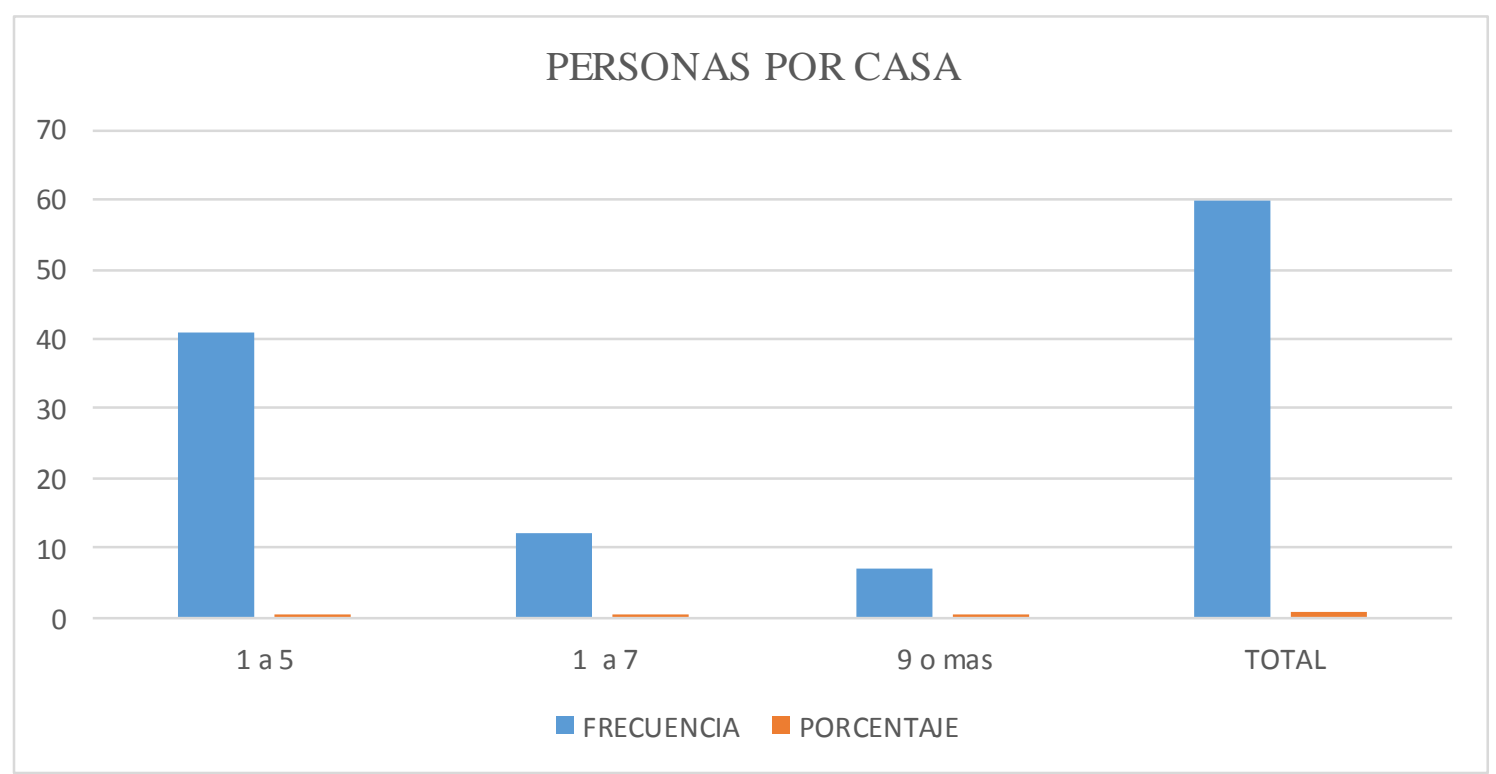

Figura 1. Representación de personas por edades.

\section{Análisis o interpretación:}

Con un total de 60 casa encuestada se llegó a que en el 68\% de las casa hay entre 1 a 5 personas, en el $20 \%$ hay de 1 a 7 personas y en el 11\% hay 9 o más personas que habitan por casa.

Tabla 2.- ¿Cuál es el tipo de vivienda en el que habita?

\begin{tabular}{|l|l|l|}
\hline ALTERNATIVAS & FRECUENCIA & PORCENTAJE \\
\hline MADERA & 6 & $10 \%$ \\
\hline MIXTA & 8 & $13 \%$ \\
\hline HORMIGON ARMADO & 3 & $5 \%$ \\
\hline
\end{tabular}




\begin{tabular}{|l|l|l|}
\hline LADRILLO & 43 & $71 \%$ \\
\hline TOTAL & 60 & $100 \%$ \\
\hline
\end{tabular}

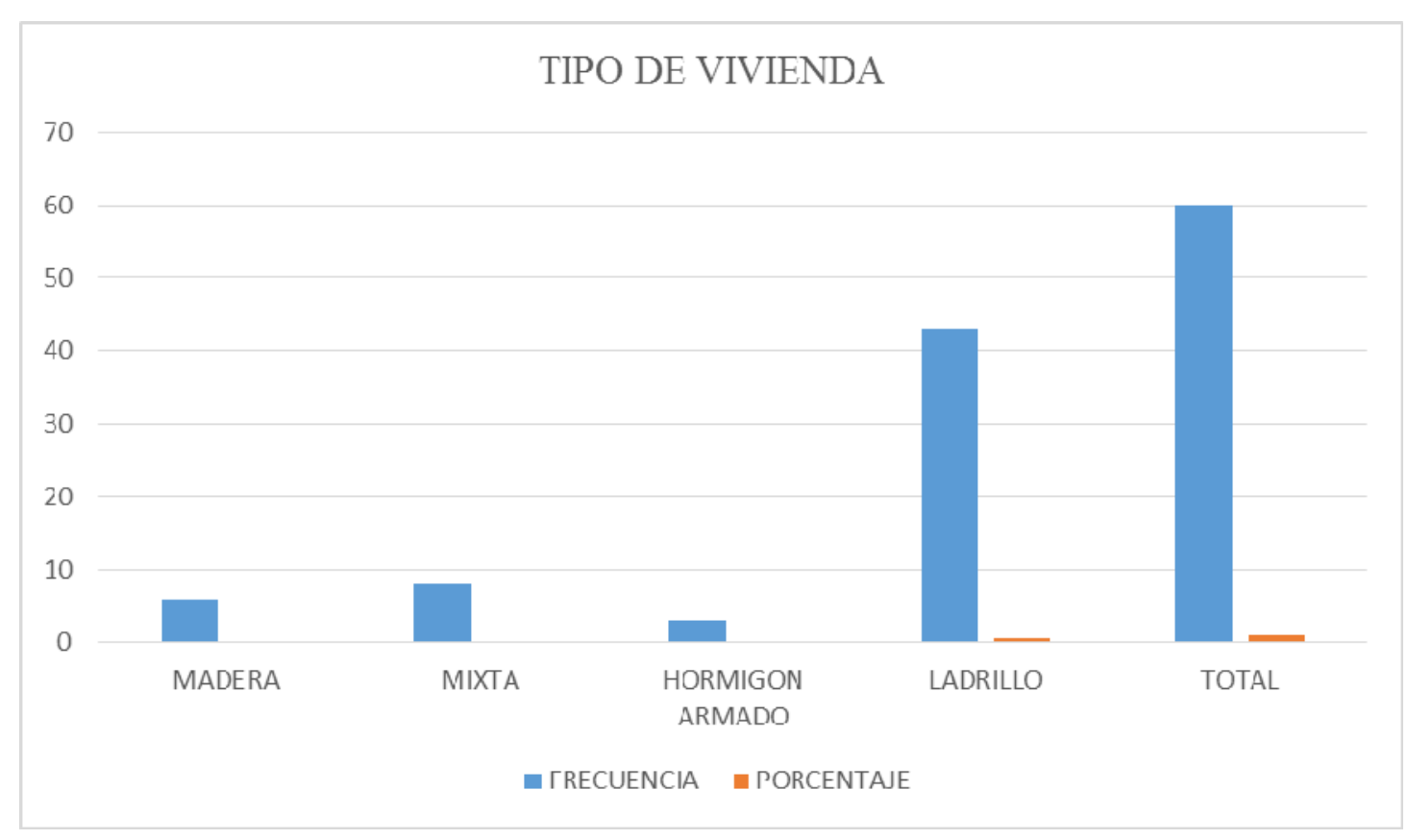

Figura 2. Representación según tipo de viviendas

\section{Análisis o interpretación:}

Con un total de 60 casas encuestadas el 6\% son de madera, el 13\% son de construcción mixta, el 5\% son de hormigón armado y el 71\% son de ladrillo.

Tabla 3.- ¿Qué clase de alumbrado se emplea en la cocina, en el establo, en los dormitorios?

\begin{tabular}{|l|l|l|}
\hline ALTERNATIVAS & FRECUENCIA & PORCENTAJE \\
\hline LUZ NATURAL & 6 & $10 \%$ \\
\hline FOCOS & 53 & $88 \%$ \\
\hline LÁMPARAS & 1 & $1 \%$ \\
\hline TOTAL & 60 & $100 \%$ \\
\hline
\end{tabular}




\section{TIPO DE ALUMBRADO}

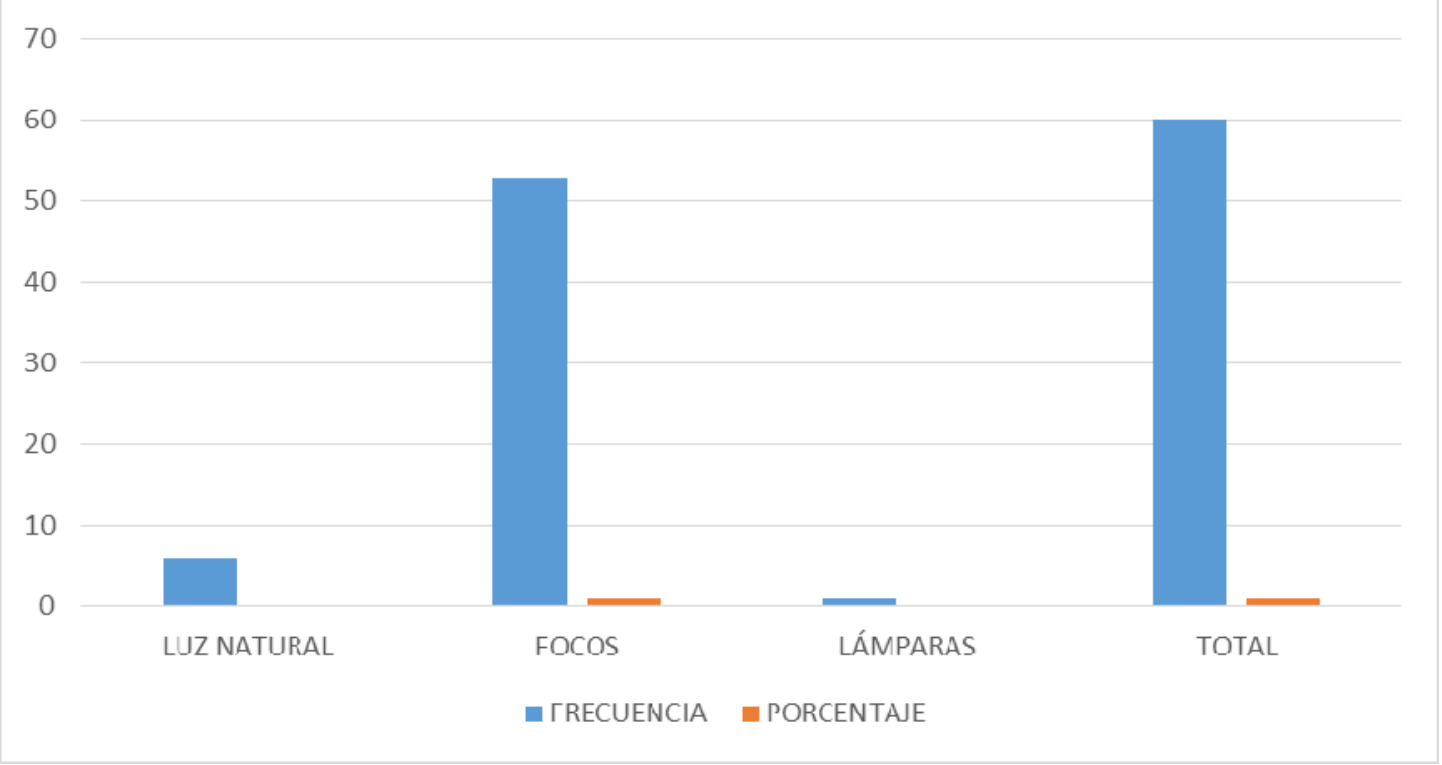

Figura 3. Representación según tipo de alumbrado

\section{Análisis o interpretación:}

Con un total de 60 casas encuestadas en el 10\% de las casas se emplea la luz natural, en el $88 \%$ se emplean focos para iluminar la casa y solo el 1\% utiliza lámparas.

Tabla 4.- ¿Qué construcciones complementarias acompañan a la casa y cuál es su situación con respecto a la misma?

\begin{tabular}{|l|l|l|}
\hline ALTERNATIVAS & FRECUENCIA & PORCENTAJE \\
\hline GRANJAS & 1 & $1 \%$ \\
\hline CHIQUEROS & 1 & $1 \%$ \\
\hline GALLINEROS & 28 & $46 \%$ \\
\hline REFUGIOS & 0 & $0 \%$ \\
\hline BORDAS & 0 & $0 \%$ \\
\hline PAJARES & 0 & $0 \%$ \\
\hline NINGUNO & 30 & $50 \%$ \\
\hline TOTAL & 60 & $100 \%$ \\
\hline
\end{tabular}




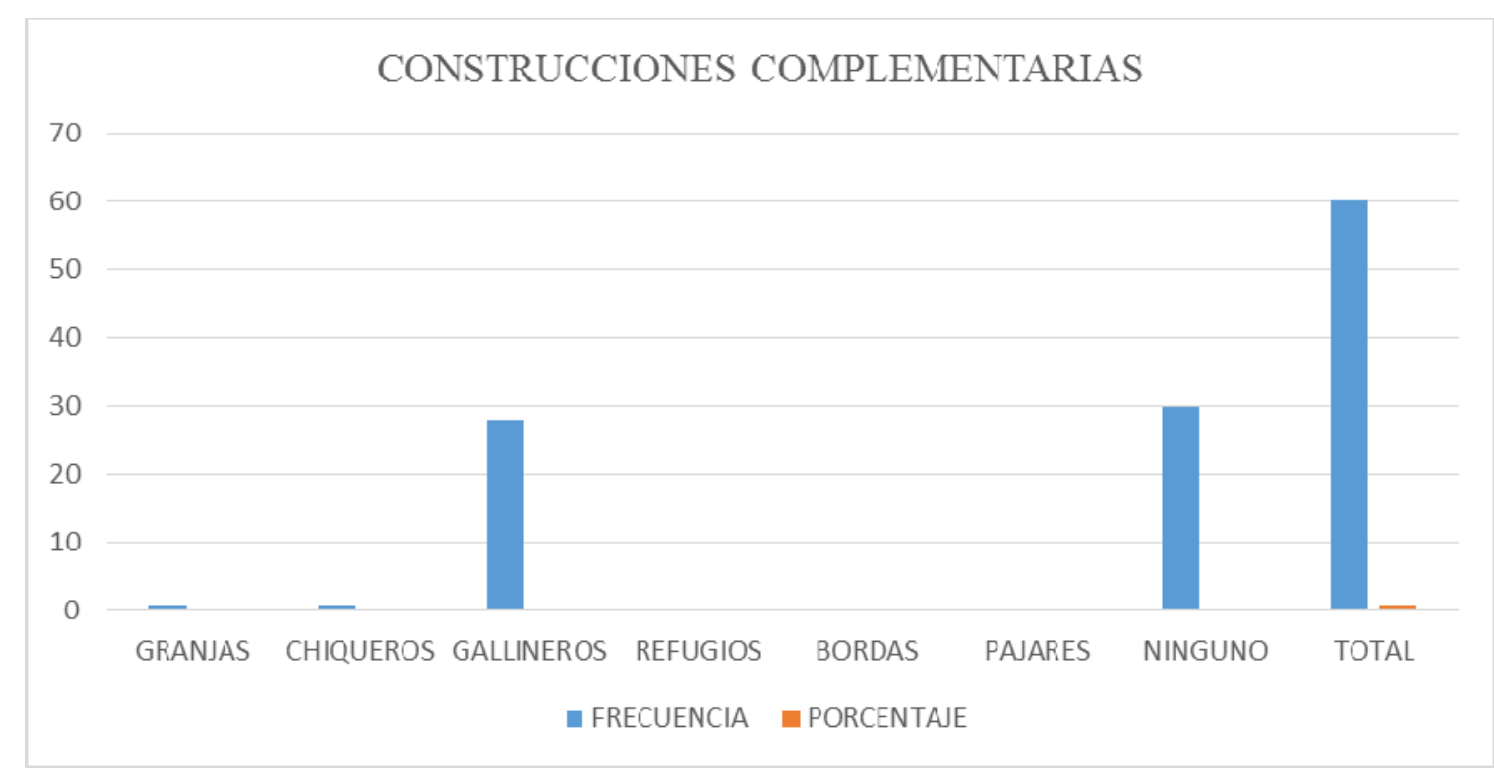

Figura 4. Representación según tipo de construcción complementaria

\section{Análisis o interpretación:}

Con un total de 60 casas encuestadas un 1\% tiene granjas otro 1\% tiene chiqueros, el $46 \%$ tiene gallineros y un 50\% no tiene ningún tipo de construcción complementaria.

Tabla 5.- Al momento de terminar la construcción de una casa ¿Se bendice o se realiza algún tipo de ritual?

\begin{tabular}{|l|l|l|}
\hline ALTERNATIVAS & FRECUENCIA & PORCENTAJE \\
\hline SI & 24 & $40 \%$ \\
\hline NO & 36 & $60 \%$ \\
\hline TOTAL & 60 & $100 \%$ \\
\hline
\end{tabular}




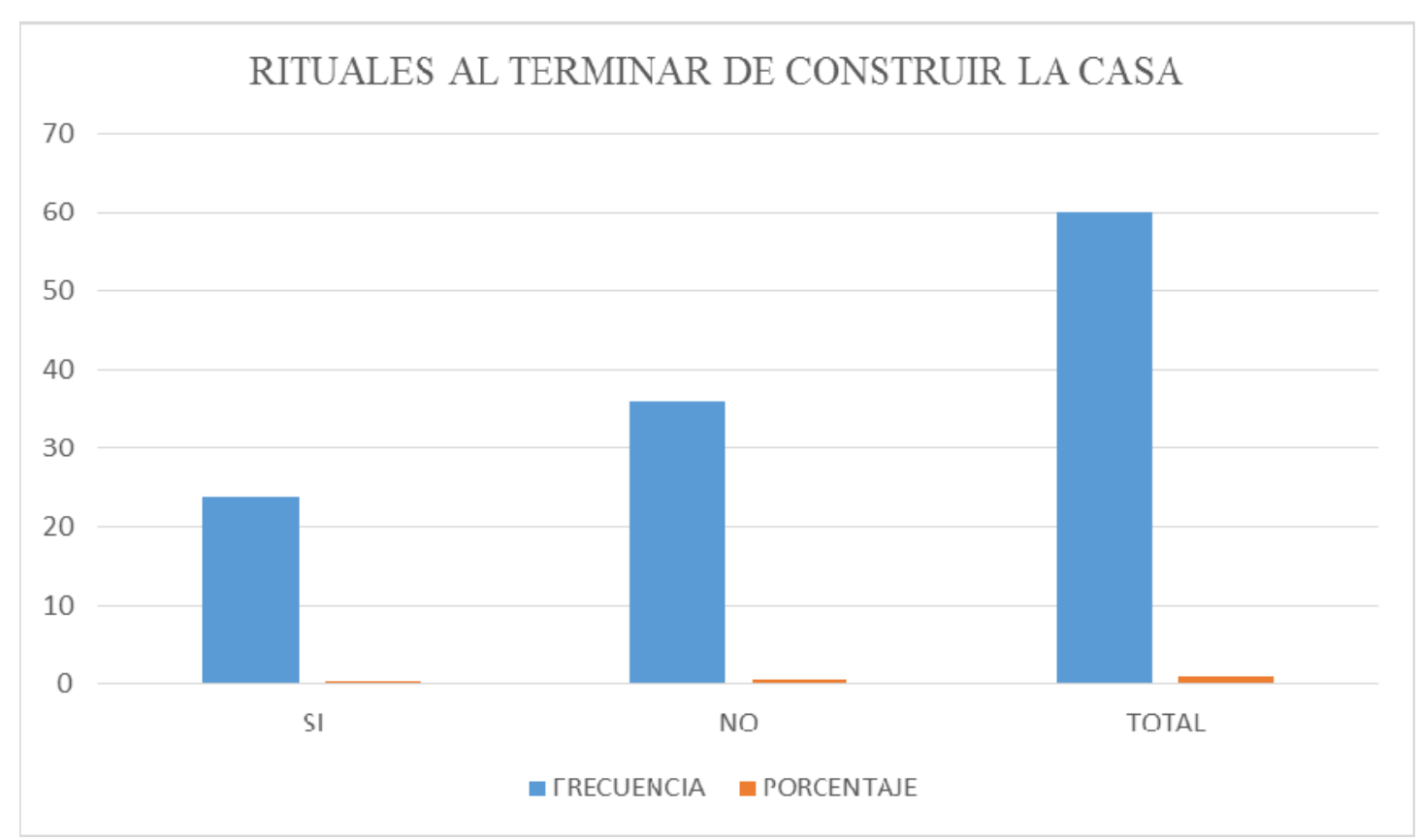

Figura 5. Representación según práctica de rituales

\section{Análisis o interpretación:}

Con un total de 60 casas encuestadas el $40 \%$ de las casas si han bendecido o realizado algún tipo de ritual a sus casas al momento de terminarlas de construir y un $60 \%$ no ha realizado ninguna de estas actividades.

Tabla 6.- ¿Cuántas veces se come al día y qué nombre recibe cada una de estas comidas?

\begin{tabular}{|l|l|l|}
\hline ALTERNATIVAS & FRECUENCIA & PORCENTAJE \\
\hline $\mathbf{1}-\mathbf{2}$ & 1 & $1 \%$ \\
\hline $\mathbf{1}-\mathbf{3}$ & 55 & $91 \%$ \\
\hline $\mathbf{4}$ o más & 4 & $6 \%$ \\
\hline TOTAL & 60 & $100 \%$ \\
\hline
\end{tabular}




\section{COMIDAS DIARIAS}

70

60

50

40

30

20

10

0

1 a 2

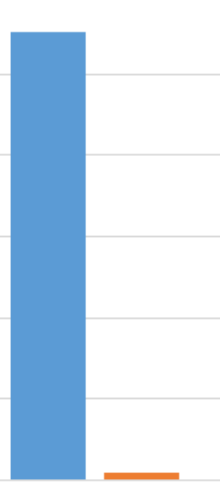

1 a 3

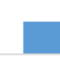

4 o mas

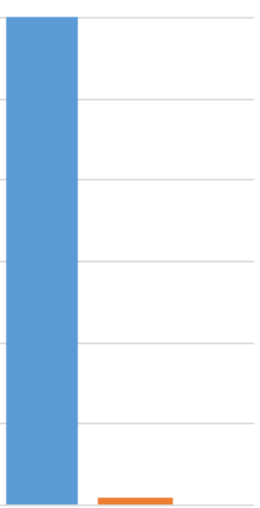

TOTAL

- FRECUENCIA - PORCENTAJE

Figura 6. Representación según frecuencias de comidas diarias

\section{Análisis o interpretación:}

Con respecto a la pregunta ¿Cuántas veces se come al día y qué nombre recibe cada una de estas comidas? El 1\% de los encuestados comen entre 1 a 2 veces al día, el 91\% come entre 1 a 3 veces al día y un $6 \%$ come 4 o más veces al día y estas llevan los nombres comunes de desayuno, almuerzo y merienda.

Tabla 7.- ¿Qué se bebe en cada clase de comida?

\begin{tabular}{|l|l|l|}
\hline ALTERNATIVAS & FRECUENCIA & PORCENTAJE \\
\hline AGUA & 22 & $32 \%$ \\
\hline JUGOS & 40 & $58 \%$ \\
\hline REFRESCOS & 6 & $8 \%$ \\
\hline TOTAL & 68 & $100 \%$ \\
\hline
\end{tabular}




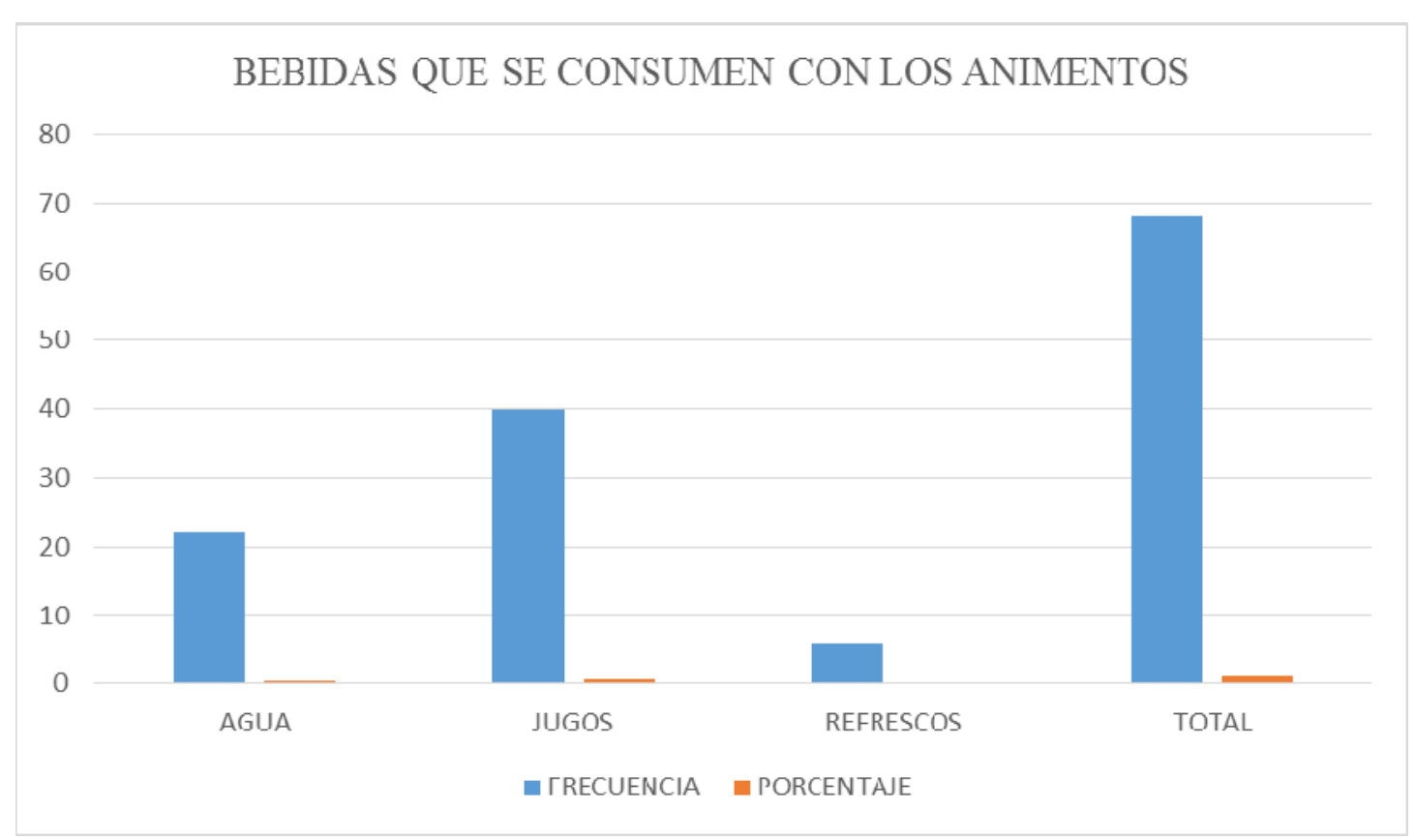

Figura 7. Representación según frecuencia de bebidas consumidas con alimentos

\section{Análisis o interpretación:}

Con un total de 68 opiniones recolectadas en las encuestas realizadas a 60 casas un 32\% bebe agua con las comidas, el $58 \%$ bebe jugos y un $8 \%$ consume refrescos con los alimentos.

Tabla 8.- ¿Cómo se preparan y con qué se condimentan las comidas ordinarias?

\begin{tabular}{|l|l|l|}
\hline ALTERNATIVAS & FRECUENCIA & PORCENTAJE \\
\hline COCINA A LEÑA & 8 & $13 \%$ \\
\hline COCINA A GAS & 52 & $86 \%$ \\
\hline TOTAL & 60 & $100 \%$ \\
\hline
\end{tabular}




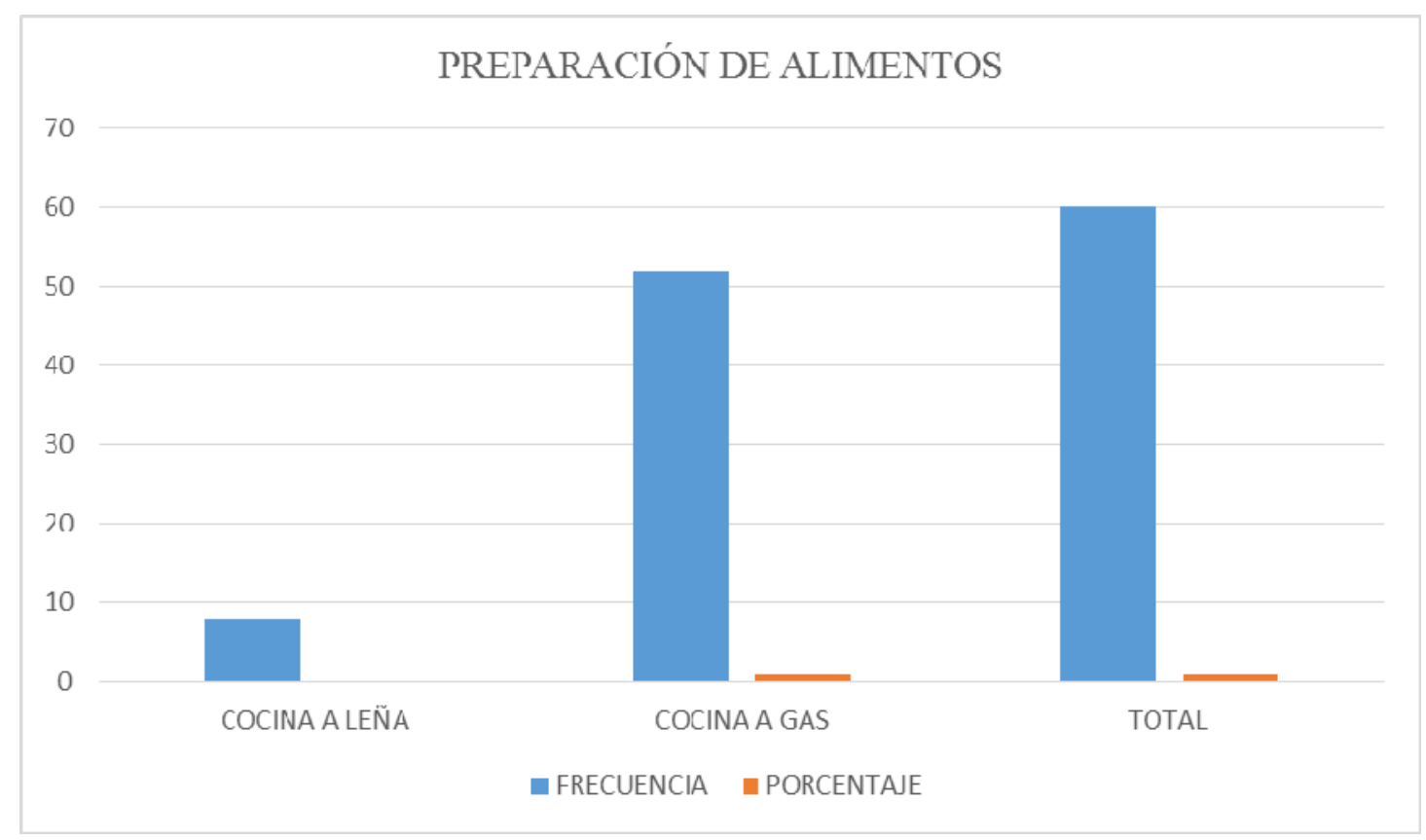

Figura 8. Representación según frecuencia de preparación de alimentos

\section{Análisis o interpretación:}

Con un total de 60 casas encuestadas en el 13\% de ella se utiliza la cocina a leña y en el $86 \%$ de usa la cocina a gas y por ende suele ser la más común.

Tabla 9.- ¿Se bebe vino? ¿Sidra? ¿Licores?

\begin{tabular}{|l|l|l|}
\hline ALTERNATIVAS & FRECUENCIA & PORCENTAJE \\
\hline SI & 8 & $13 \%$ \\
\hline NO & 52 & $86 \%$ \\
\hline TOTAL & 60 & $100 \%$ \\
\hline
\end{tabular}




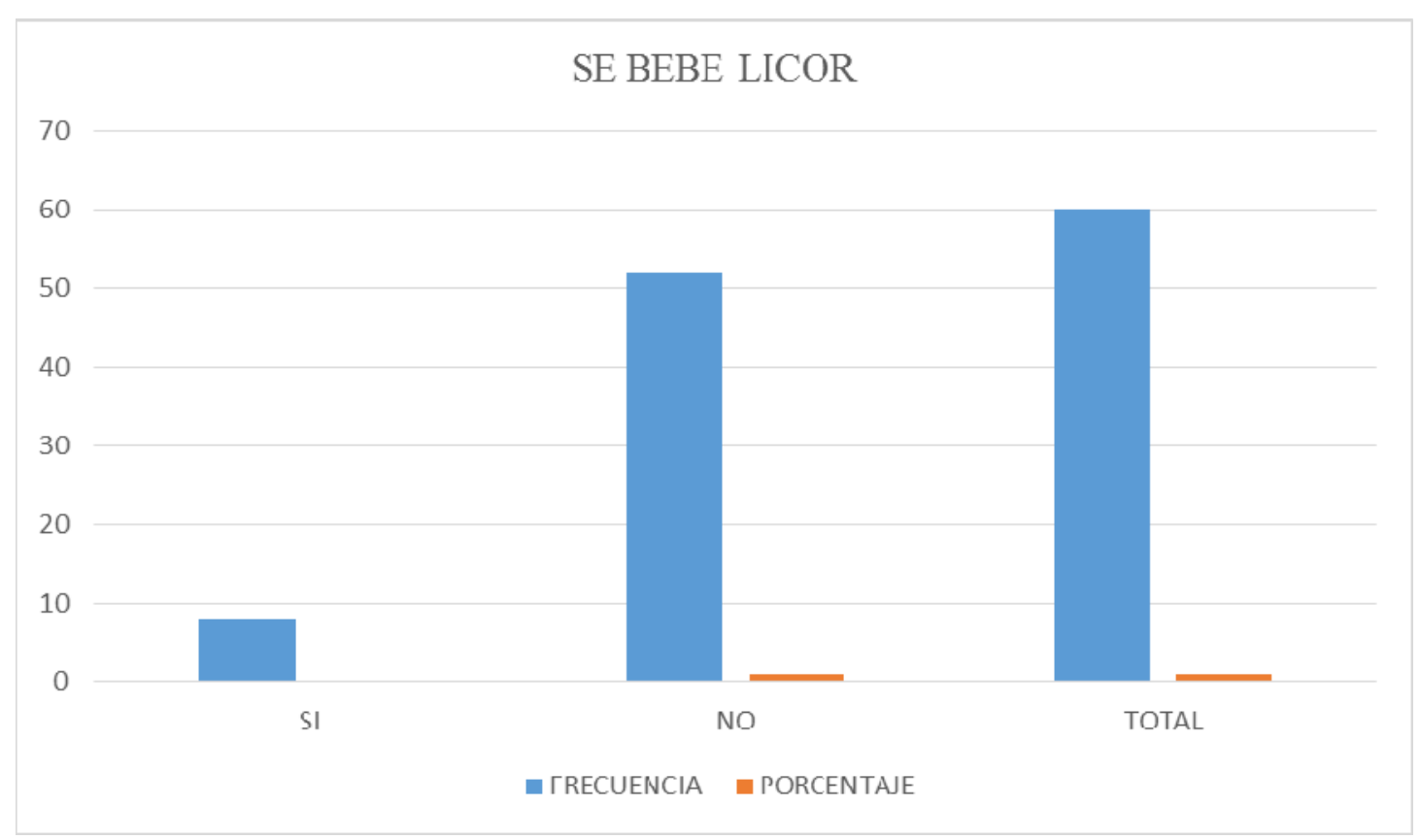

Figura 9. Representación según frecuencia de consumo de licores

\section{Análisis o interpretación:}

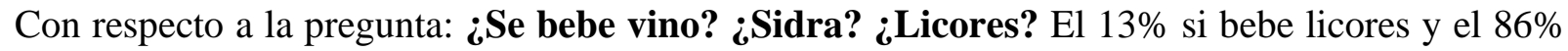
no bebe ningún tipo de licor.

Tabla 10.- ¿Existen trajes o vestidos tradicionales?

\begin{tabular}{|l|l|l|}
\hline ALTERNATIVAS & FRECUENCIA & PORCENTAJE \\
\hline SI & 6 & $10 \%$ \\
\hline NO & 54 & $90 \%$ \\
\hline TOTAL & 60 & $100 \%$ \\
\hline
\end{tabular}




\section{EXISTENCIA DE TRAJES TRADICIONALES}

70

60

50

40

30

20

10

0

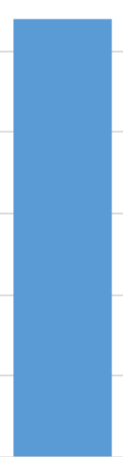

SI

NO

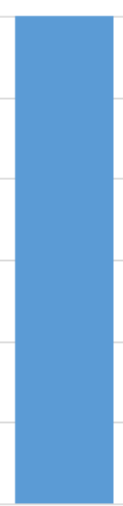

TOTAL

- FRECUENCIA - PORCENJATE

Figura 10. Representación según existencia de trajes tradicionales

\section{Análisis o interpretación:}

Con respecto a la pregunta: ¿Existen trajes o vestidos tradicionales? El 10\% de los encuestados dicen que si existen trajes tradicionales y el $90 \%$ dice que no existen.

Tabla 11.- ¿Se llevan medallas religiosas?

\begin{tabular}{|l|l|l|}
\hline ALTERNATIVAS & FRECUENCIA & PORCENTAJE \\
\hline SI & 7 & $11 \%$ \\
\hline NO & 53 & $88 \%$ \\
\hline TOTAL & 60 & $100 \%$ \\
\hline
\end{tabular}




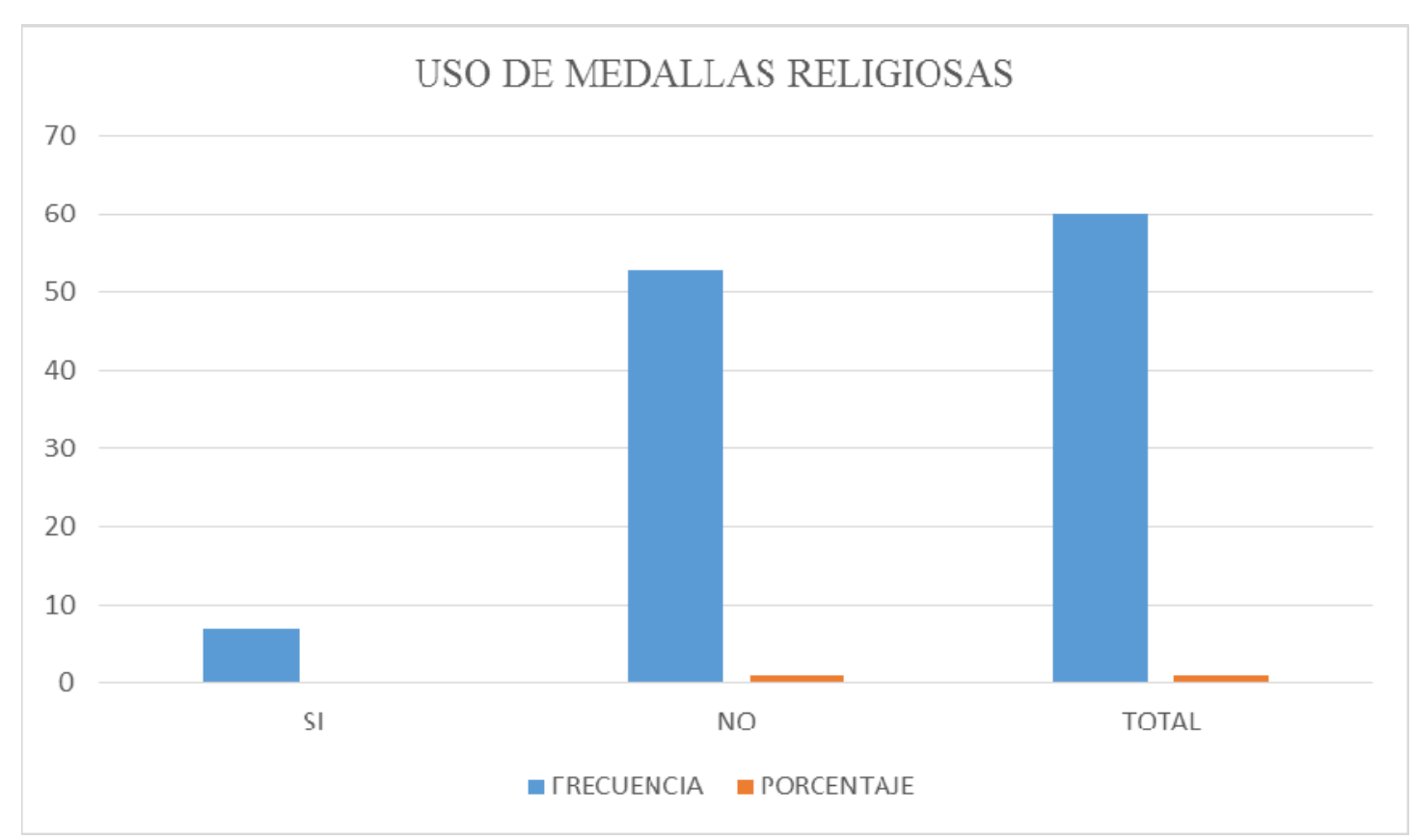

Figura 11. Representación según uso de medallas religiosas

\section{Análisis o interpretación:}

Con respecto a la pregunta: ¿ Se llevan medallas religiosas? El 11\% de los encuestados si llevan medallas religiosas y el 88\% no llevan.

Tabla 12- ¿Existen artesanos en la comunidad?

\begin{tabular}{|l|l|l|}
\hline ALTERNATIVAS & FRECUENCIA & PORCENTAJE \\
\hline SI & 60 & $100 \%$ \\
\hline NO & 0 & $0 \%$ \\
\hline TOTAL & 60 & $100 \%$ \\
\hline
\end{tabular}




\section{ARTESANOS EN LA COMUNIDAD}

70

60

50

40

30

20

20

10

0

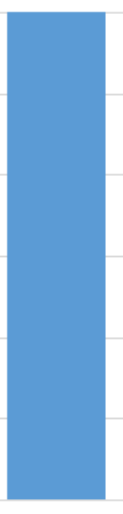

SI

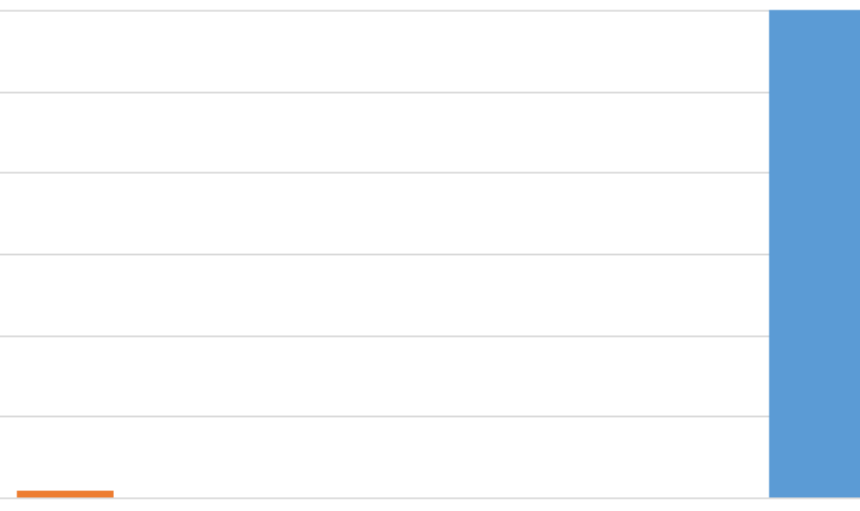

NO

TOTAL

- FRECUENCIA $\square$ PORCENTAJE

Figura 12. Representación según presencia de artesanos en la comunidad

\section{Análisis o interpretación:}

Con respecto a la pregunta: ¿Existen artesanos en la comunidad? El 100\% de los encuestados afirman que si hay artesanos en la comunidad.

Tabla 13.- ¿Qué tipo de artesanías producen?

\begin{tabular}{|l|l|l|}
\hline ALTERNATIVAS & FRECUENCIA & PORCENTAJE \\
\hline HERRERÍA & 1 & $1 \%$ \\
\hline ALFARERIA & 1 & $1 \%$ \\
\hline TEJIDO & 58 & $96 \%$ \\
\hline OTROS & 0 & $0 \%$ \\
\hline TOTAL & 60 & $100 \%$ \\
\hline
\end{tabular}




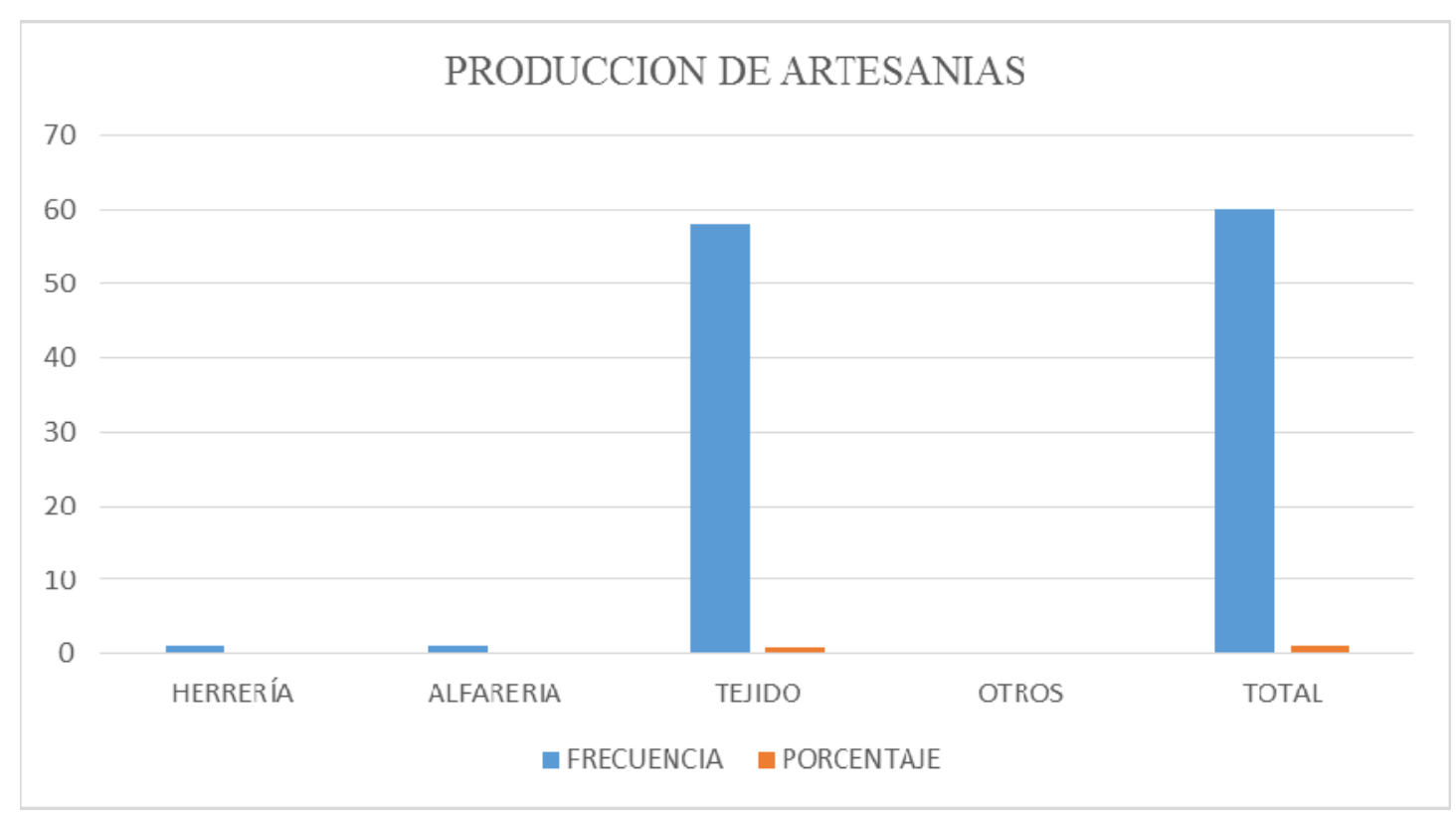

Figura 13. Representación según producciones artesanales

\section{Análisis o interpretación:}

Con respecto a la pregunta: ¿Qué tipo de artesanías producen? El 1\% de los encuestados dicen que se realiza la herrería, otro $1 \%$ la alfarería y el $96 \%$ dice que se realiza el tejido dentro de la comunidad.

Con base a la información levantada en las encuestas y entrevistas se determinó que el modo de vida o profesiones practicados por los residentes de la comunidad Pile, son la fabricación, tejido y comercio del sombrero fino de paja toquilla. La especie utilizada es Carludovica palmata Ruiz \& Pav., perteneciente a la familia Cyclanthaceae, no es una verdadera palma, pero está relacionada con estas por pertenecer al mismo orden de las espatifloras. Es una planta herbácea de 1,5 a 2,5 m de altura, sin un tallo visible. Posee hojas simples, agrupadas y que conforman una roseta, con láminas de hasta $65 \mathrm{~cm}$ de largo, en forma de abanico, plegadas y con los bordes aserrados. Según Govaerts (2019), se distribuye por las Islas del Caribe (Belice, Bermuda, Cuba, República Dominicana, Haití, Jamaica, Puerto Rico, Trinidad-Tobago) América Central (Costa Rica, México, Nicaragua, Panamá) y América del Sur (Bolivia; norte del Brasil, Colombia, Ecuador, El Salvador, Guatemala, Honduras, Perú, Venezuela). Está catalogada como de preocupación menor en la lista roja de la Unión Internacional para la Conservación de la Naturaleza (UICN) (Brummitt, 2013).

Carludovica palmata Ruiz \& Pav crece en sitios abiertos y perturbados, también se encuentra cultivada en el área. Los residentes aprovechan sus fibras suaves, flexibles y duraderas, para tejer sombreros y otros artículos. La mayoría de su producción se vende a minoristas o a intermediarios y algunos son para uso propio. Sus frutos son comestibles, al igual que las bases de los brotes de las hojas sin abrir. Estos usos coinciden con los reportados por Bennett et al. (1992) para la zona amazónica, la cual es utilizada por los pueblos indígenas tales como shuar, achuar y quichua. 
Juan Francisco Villamar González, Luis David Zambrano Figueroa, Héctor Simón Pinargote Vélez

Estudios realizados por Basurto-Cedeño y Cevallos (2018) demuestran el inmenso valor cultural y la tradición milenaria que es el principal sustento de los habitantes de Pile. En este sentido el tejido fino de paja es considerada una tradición mágica que tiene sus raíces en el periodo de formación, y que se ha transmitido de generación en generación. En la actualidad el sombrero fino de paja toquilla goza de fama internacional, pero paradójicamente sus fabricantes viven en la pobreza y son los intermediarios quienes se benefician económicamente de la venta de este producto tradicional, lo que está propiciando una falta de empoderamiento de los jóvenes y migración de los habitantes de la comunidad.

La arquitectura vernácula de Pile, está relacionada con la tradición del tejido, es decir, la vivienda del artesano y su entorno, como elemento clave de la producción de la artesanía. No solo es el espacio, sino también las condiciones internas y el proceso de transmisión a las nuevas generaciones dentro de esta estructura doméstica, lo que convierte a la vivienda tradicional en un componente relevante para su comunidad (Macías Mendoza, 2019). A pesar de la Declaratoria del Tejido Tradicional del Sombrero de Paja Toquilla en la Lista de Patrimonios Culturales Intangibles de la Humanidad, las condiciones de vida de los tejedores no han mejorado, por lo que el interés de los jóvenes en continuar con la tradición se observa amenazada (Benavides Maldonado et al., 2019).

A través de encuestas realizadas a los residentes, se obtuvo los productos que más suelen cultivarse, sin embargo, estos productos en su mayoría son para el consumo propio y no para la comercialización, tales como son Citrus $\times$ limon (L.) Burm.f., Musa spp. y Zea mays L En cuanto a la fauna, en la parte montañosa se pueden observar las especies de mamíferos en peligro de extinción tales como Alouatta palliata (Gray, 1849), Cuniculus paca (Linnaeus, 1766) y Dasyprocta punctata Gray, 1842, que la población la considera importante como atractivo turístico.

La comunidad Pile cuenta con mucho potencial turístico debido a las propias características que la diferencia de las zonas aledañas, con una variedad de flora y fauna y una belleza paisajística que la cataloga dentro de la clase "A" como una área de calidad alta, con rasgos singulares y sobresalientes, además con un mínimo impacto ambiental provocado por los pobladores, los cuales se esfuerzan por preservar el medio que los rodea, es una comunidad que se presta para desarrollar varias actividades y modalidades turísticas. Los resultados obtenidos indican la necesidad de fortalecer el turismo de naturaleza, patrimonial y cultural, como una vía para mejorar las condiciones de vida de la población.

\section{FICHA ETNOGRAFICA}

\section{Determinación etnográfica de la comunidad "Pile"}

\begin{tabular}{|c|c|c|}
\hline \multicolumn{2}{|l|}{ Idioma: Castellano } & Etnia: Mestiza \\
\hline \multicolumn{2}{|l|}{ Religión: } & Cultura: Montubia \\
\hline \multirow{2}{*}{\multicolumn{2}{|c|}{ Sistema de Población: casas agrupadas }} & DESCRIPCIÓN \\
\hline & & PILE \\
\hline Sistema & Los modos de vida u otras & - Construcción \\
\hline
\end{tabular}

264 UNESUM-Ciencias. Publicación cuatrimestral. Vol. 5, Año 2021, No. 3 (Mayo-Agosto) 
Publicación cuatrimestral. Vol.5, No. 3 (Mayo-Agosto), Año 2021. Pág. 247-272 TOURIST INFORMATION OF THE PILE COMMUNITY

\begin{tabular}{|c|c|c|}
\hline \multirow[t]{4}{*}{ Producción } & $\begin{array}{l}\text { profesiones practicados } \\
\text { por los habitantes de este } \\
\text { lugar }\end{array}$ & $\begin{array}{ll}\text { - } & \text { Tejido } \\
\text { - } & \text { Comercio }\end{array}$ \\
\hline & ¿Qué Productos Producen? & $\begin{array}{ll}\text { - } & \text { Maíz } \\
\text { - } & \text { Plátano } \\
\text { - } & \text { Paja toquilla } \\
\text { - } & \text { Limones }\end{array}$ \\
\hline & Para quienes producen & $\begin{array}{l}\text { Tanto para consumo propio como para la } \\
\text { venta }\end{array}$ \\
\hline & Modo de Producción & Producción domestica \\
\hline \multirow{6}{*}{ VIVIENDA } & Tipos de Vivienda & $\begin{array}{ll}\text { - } & \text { Madera (10\%) } \\
\text { - } & \text { Mixta (13\%) } \\
\text { - } & \text { Hormigón armado (5\%) } \\
\text { - } & \text { Ladrillo (71\%) }\end{array}$ \\
\hline & $\begin{array}{l}\text { Existe algún tipo de rito al } \\
\text { empezar a construir la casa }\end{array}$ & $\begin{array}{l}\text { En su mayoría no existe ningún rito, en muy } \\
\text { pocas casas se bendice. }\end{array}$ \\
\hline & $\begin{array}{l}\text { Existen objetos decorativos } \\
\text { religiosos }\end{array}$ & En muy pocas casas hay objetos religiosos \\
\hline & $\begin{array}{l}\text { Clase de Alumbrado que se } \\
\text { emplea en el hogar }\end{array}$ & Luz eléctrica (Focos) \\
\hline & $\begin{array}{l}\text { Construcciones } \\
\text { complementarias } \\
\text { acompañan la casa }\end{array}$ & Gallineros \\
\hline & $\begin{array}{l}\text { Medidas de protección } \\
\text { para la casa }\end{array}$ & No \\
\hline \multirow{4}{*}{ VESTIMENTA } & $\begin{array}{l}\text { Horarios, nombres } \\
\text { lugares de cada comida }\end{array}$ & $\begin{array}{l}\text { - } 6: 30 \text { - café - mesa } \\
\text { - 12:30 - almuerzo - mesa } \\
\text { - 19:00 - merienda - mesa }\end{array}$ \\
\hline & $\begin{array}{l}\text { condimentos para la } \\
\text { alimentación }\end{array}$ & $\begin{array}{l}\text { Condimentos naturales } \\
\text { Condimentos industriales }\end{array}$ \\
\hline & Tipo de cocina & $\begin{array}{l}\text { Cocina a gas, aunque en algunas ocasiones } \\
\text { también se usa la cocina a leña }\end{array}$ \\
\hline & Comidas $\mathrm{y}$ bebidas en & Navidad, año nuevo y cumpleaños; cerdo y \\
\hline
\end{tabular}




\begin{tabular}{|c|c|c|}
\hline \multicolumn{3}{|c|}{ Juan Francisco Villamar González, Luis David Zambrano Figueroa, Héctor Simón Pinargote Vélez } \\
\hline & fechas especiales & $\begin{array}{l}\text { gallina } \\
\text { Novenas y velorios; sanduches, greñoso. }\end{array}$ \\
\hline & $\begin{array}{l}\text { Descripción de vestimenta } \\
\text { tradicional en fechas } \\
\text { especiales }\end{array}$ & No existe vestimenta tradicional \\
\hline & $\begin{array}{l}\begin{array}{l}\text { Diferencia de la } \\
\text { indumentaria }\end{array} \text { entre } \\
\text { solteros y casados } \\
\text { libre }\end{array}$ & $\begin{array}{l}\text { En cuanto a las personas que son casadas } \\
\text { ellos visten ropas más cautas a diferencia de } \\
\text { las solteras que tiene mucha más libertad de } \\
\text { vestir lo que deseen. }\end{array}$ \\
\hline & $\begin{array}{l}\text { Adornos que llevan en su } \\
\text { cuerpo (vestido, cabeza, } \\
\text { muñecas, cuello y orejas) }\end{array}$ & No \\
\hline & $\begin{array}{lcr}\text { Medidas de protección } \\
\text { personal } & \text { (amuletos } \quad \text { o } \\
\text { medallas) } & & \end{array}$ & $\begin{array}{l}\text { En su mayoría no llevan ningún tipo de } \\
\text { medallas. }\end{array}$ \\
\hline \multirow{4}{*}{$\begin{array}{l}\text { Manifestaciones } \\
\text { Culturales }\end{array}$} & Fiestas Patronales & 28 de diciembre \\
\hline & Música y baile & $\begin{array}{l}\text { En la comunidad esto no es de relevancia ya } \\
\text { que no suelen realizarse estas } \\
\text { manifestaciones. }\end{array}$ \\
\hline & $\begin{array}{l}\text { Tradiciones y expresiones } \\
\text { orales }\end{array}$ & $\begin{array}{l}\text { En el fallecimiento de un familiar se } \\
\text { mantiene el color negro en prendas de vestir } \\
\text { por un tiempo de determine la persona que } \\
\text { esté de duelo. }\end{array}$ \\
\hline & Juegos Tradicionales & $\begin{array}{l}\text { Los juegos tradicionales son el ensacado, la } \\
\text { rayuela, el escondido, el quemado, entre } \\
\text { otros. }\end{array}$ \\
\hline
\end{tabular}

\begin{tabular}{|c|c|c|c|c|}
\hline \multicolumn{5}{|c|}{$\begin{array}{lllllll}\text { ANALIZAR } & \text { ESTADÍSTICAMENTE } & \text { LA } & \text { ACTIVIDAD } & \text { DE } & \text { PRODUCCIÓN } & \text { Y } \\
\text { DISTRIBUCIÓN ECONÓMICA. } & & & & & \end{array}$} \\
\hline \multicolumn{5}{|c|}{ ESTADISTICAMENTE } \\
\hline \multicolumn{5}{|c|}{ COMUNIDAD “PILE” } \\
\hline TECNICA & POBLACION & UNIVERSO & $\begin{array}{l}\text { TAMAÑO } \\
\text { DE LA } \\
\text { MUESTRA }\end{array}$ & $\begin{array}{l}10 \text { PREGUNTAS } \\
\text { O } \text { PRÁCTICAS } \\
\text { FORMULADAS }\end{array}$ \\
\hline Encuestas & $\begin{array}{l}1100 \quad \text { habitantes } \\
\text { aproximadamente }\end{array}$ & $\begin{array}{l}\text { Provincia de } \\
\text { Manabí, Cantón }\end{array}$ & $\begin{array}{lr}\text { En } & \text { la } \\
\text { comunidad } & \text { a } \\
\text { estudiar } & \text { se }\end{array}$ & $\begin{array}{l}\text { Preguntas } \\
\text { realizadas para el }\end{array}$ \\
\hline
\end{tabular}

266 UNESUM-Ciencias. Publicación cuatrimestral. Vol. 5, Año 2021, No. 3 (Mayo-Agosto) 


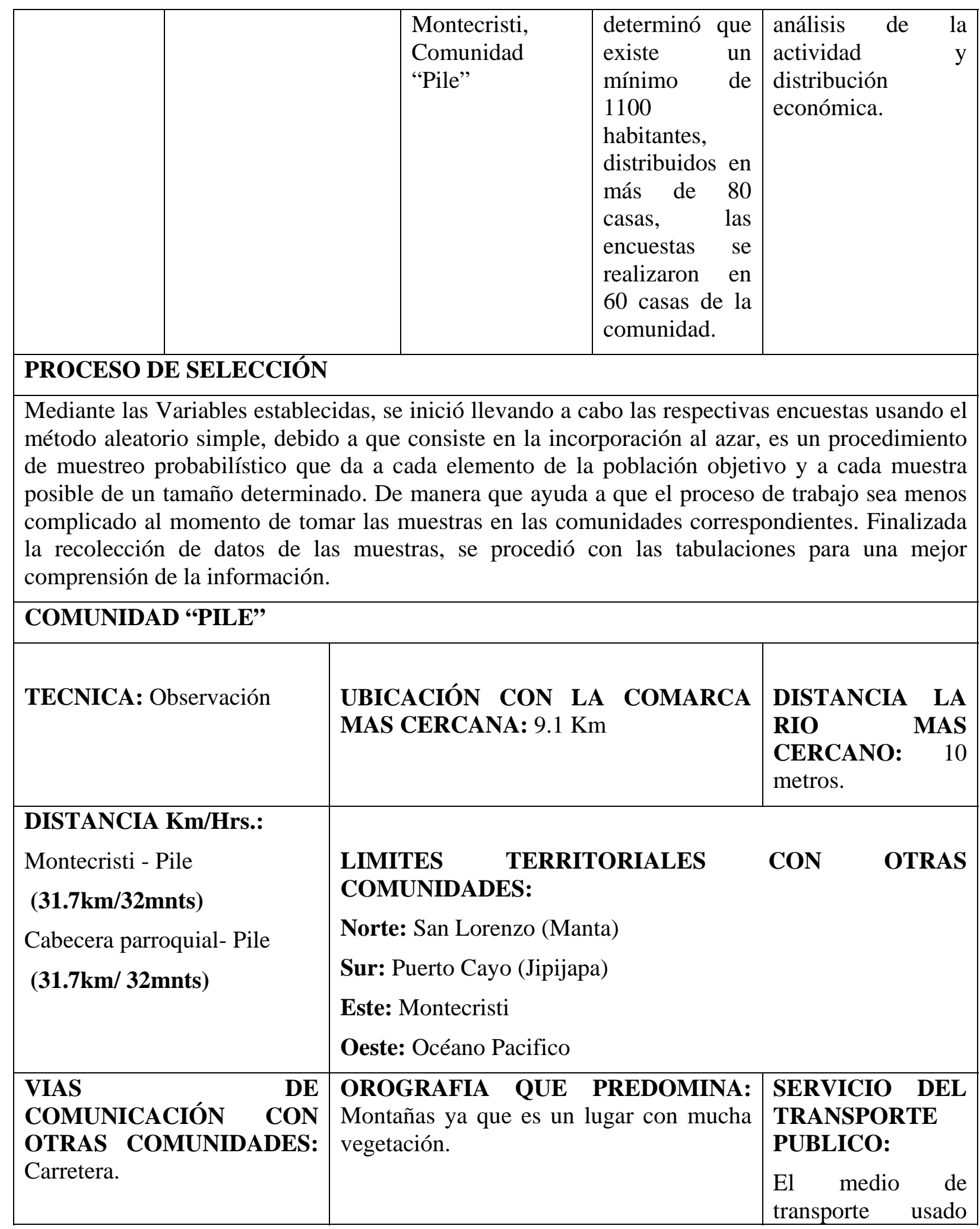




\begin{tabular}{|l|l|l|}
\hline & & $\begin{array}{l}\text { son los buses y } \\
\text { camionetas. }\end{array}$ \\
\hline ESTADO DE LAS VIAS DE COMUNICACIÓN &
\end{tabular}

Con otras comunidades: La carretera principal se encuentra casi en su totalidad en buen estado.

Dentro de la comunidad: La calle principal es tierra y no cuenta con la señalización vial necesaria.

\section{ESTADO GENERAL DE LOS EQUIPAMIENTOS $Y$ RECURSOS (INDICAR SU ESTADO Y UBICACION)}

\begin{tabular}{|c|c|c|c|}
\hline & SI & NO & DESCRIPCIÓN \\
\hline PARQUE & & $\mathbf{X}$ & $\begin{array}{l}\text { No existe parque } \\
\text { dentro de la } \\
\text { comunidad. }\end{array}$ \\
\hline CENTROS RELIGIOSOS & $\mathbf{X}$ & & $\begin{array}{l}\text { La iglesia se } \\
\text { encuentra en } \\
\text { buenas condiciones } \\
\text { y está ubicada en la } \\
\text { zona centro de la } \\
\text { comunidad. }\end{array}$ \\
\hline $\begin{array}{ll}\text { CENTROS } & \text { DE } \\
\text { SALUD/CONSULTORIOS } & \end{array}$ & $\mathbf{X}$ & & $\begin{array}{l}\text { Existe un "Sub- } \\
\text { centro de salud" y } \\
\text { se encuentra cerca } \\
\text { de la escuela. }\end{array}$ \\
\hline ENTROS EDUCATIVOS & $\mathbf{X}$ & & $\begin{array}{l}\text { La escuela que } \\
\text { existe en la } \\
\text { comunidad se } \\
\text { encuentra en un } \\
\text { buen estado y está } \\
\text { ubicada cerca de la } \\
\text { zona céntrica de la } \\
\text { comunidad. }\end{array}$ \\
\hline CEMENTERIO & $\mathbf{X}$ & & $\begin{array}{l}\text { Si existe un } \\
\text { cementerio público } \\
\text { que no se encuentra } \\
\text { en muy buenas } \\
\text { condiciones y está } \\
\text { un poco alejado de } \\
\text { la zona céntrica de } \\
\text { la comunidad. }\end{array}$ \\
\hline
\end{tabular}




\section{Existen Asociaciones de vecinos, culturales, juveniles, mujer, etc.}

Si, una asociación de tejedores y una directiva comunitaria.

Tiempo que lleva funcionando: N/S

Actividad que realiza: Llevan a cabo reuniones sobre los projectos que se quieren implementar en la comunidad, ademas las habitantes reciben capacitaciones de temas en especifico.

\section{ACTIVIDAD DE PRODUCCIÓN Y DISTRIBUCIÓN ECONÓMICA}

\section{DE “PILE”}

NIVEL DE ESTUDIO DE LA POBLACION: La mayoría no tiene ningún tipo de estudios, los jóvenes llegan a estudiar la primaria y una pequeña parte de ellos estudian la secundaria, las encuestas revelaron que es casi inexistente la educación de tercer nivel.

\section{OCUPACIÓN:}

- Tejido.

PRODUCTOS QUE SE SIEMBRAN: Los productos que más se siembran son el maíz, el plátano y la paja toquilla, pero son para uso propio, no comercial.

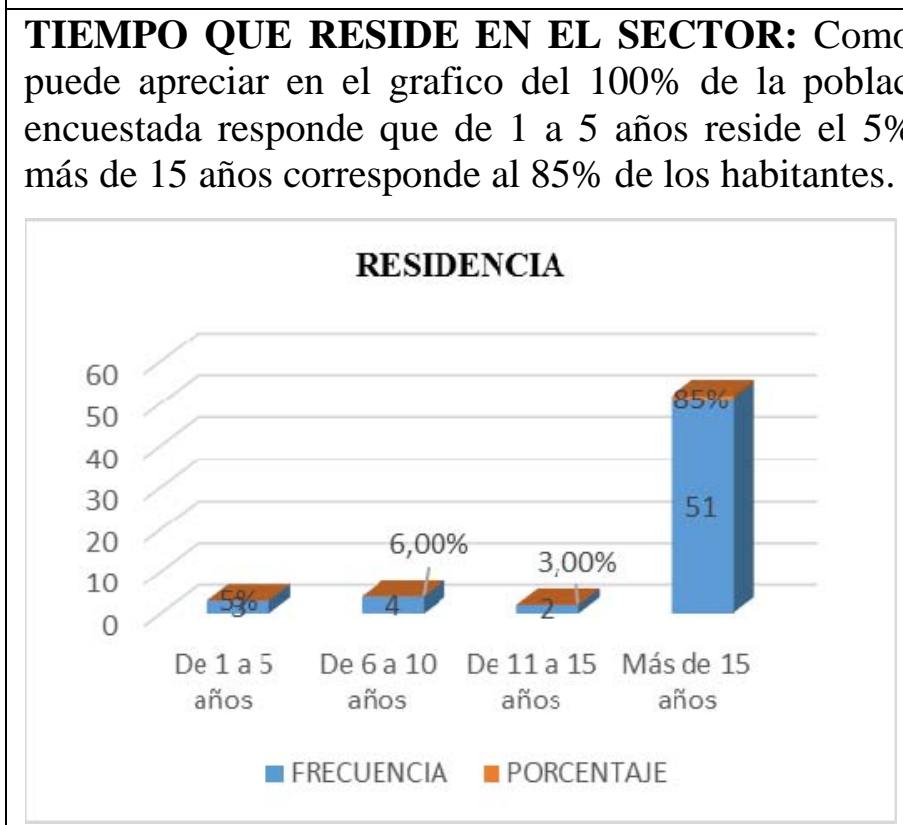

FUENTE DE FINANCIAMIENTO PARA SU ACTIVIDAD COMERCIAL: Capital Propio.

En la mayoría de los casos las personas cuentan con capital propio para realizar sus actividades, sin embargo, existen quienes reciben ingresos de familiares u otras fuentes.

EXTENSIÓN DE LA
PRODUCCIÓN ES: Al no ser una comunidad que tenga como principal actividad económica, lo poco que producen lo hacen en las zonas aledañas a sus hogares, la principal actividad que es el tejido lo hacen en sus casas.

\section{LA DISTRIBUCION DEL TEJIDO ES DISTRIBUIDA:}

La mayoría de su producción se vende a minoristas o a intermediarios y algunos son para uso propio.

CENTROS EDUCATIVOS EN LA COMUNIDAD:

En la comunidad existe un solo 
centro educativo en donde asisten los niños y jóvenes de "Pile".

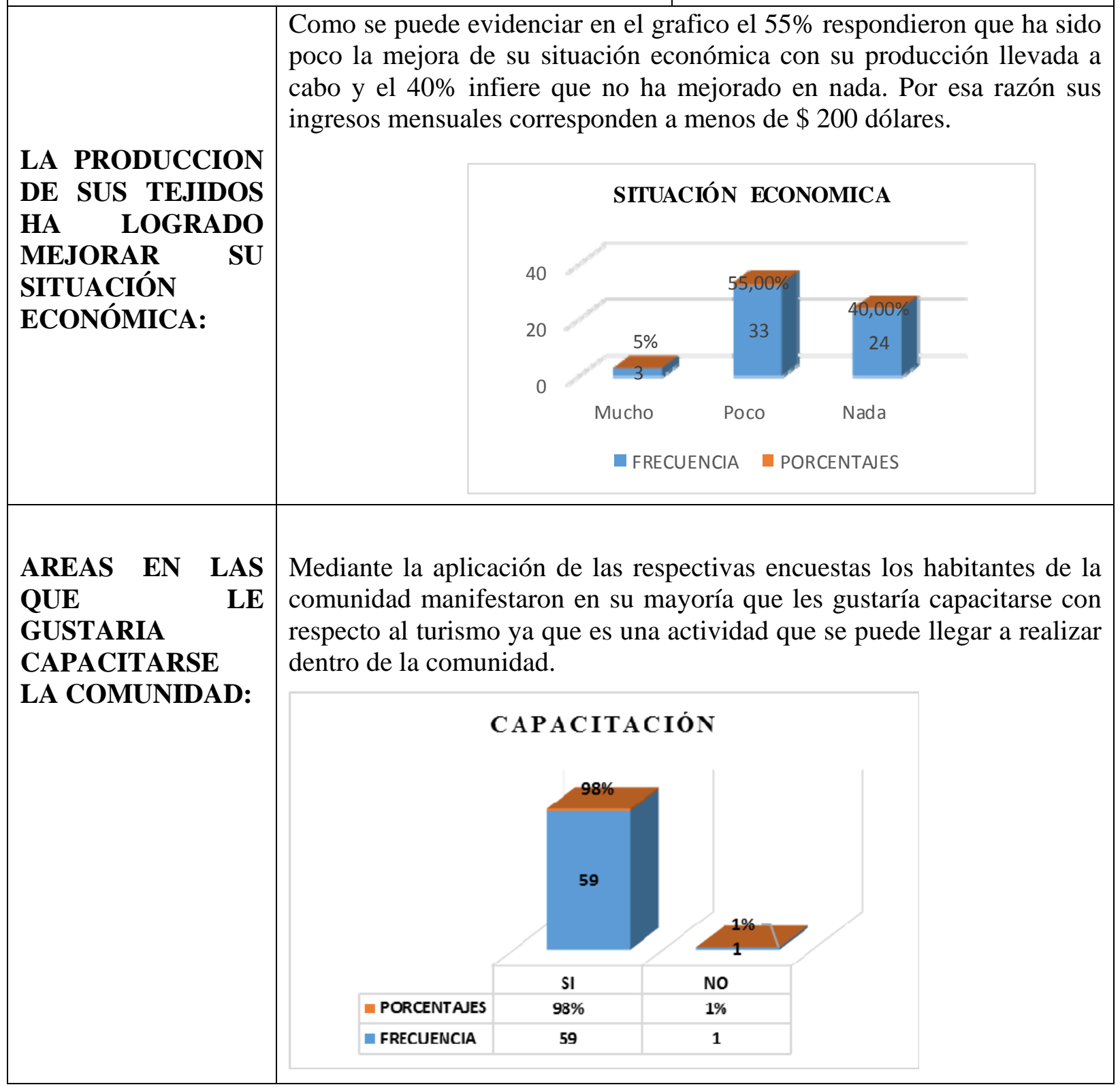

\section{CONCLUSIONES}

En la comunidad de Pile, no hay parques, existe solo un cementerio, un centro de salud, una iglesia y una escuela, estas dos últimas en buenas condiciones. Las calles son de tierra y la señal de telefonía celular es mala. 
La mayoría de los residentes no tiene estudios, los jóvenes llegan a la primaria y una pequeña parte estudian la secundaria,

El modo de vida fundamental se basa en la fabricación, tejido y comercio del sombrero fino de paja toquilla, la especie utilizada es Carludovica palmata Ruiz \& Pav.

Su potencial turístico se valoró de clase "A”, como un área de calidad alta, con rasgos singulares y sobresalientes, además con un mínimo impacto ambiental provocado por los pobladores, los cuales se esfuerzan por preservar el medio que los rodea, es una comunidad que se presta para desarrollar varias actividades y modalidades turísticas.

A nivel económico la comunidad tiene diferentes fuentes de ingresos como la construcción, el comercio y la elaboración de sombreros de paja toquilla en tejido fino, a diferencia de otras comunidades de la provincia de Manabí esta no tiene como fuente principal de ingresos la agricultura ya que la que se practica por lo general es para el consumo propio y no la comercialización de la misma, en promedio el nivel de ingresos económicos en su mayoría suele ser de menos de \$200 y muy pocas personas reciben ayudas de programas sociales.

\section{REFERENCIAS BIBLIOGRÁFICAS}

Basurto-Cedeño E. M. y Cevallos, L. (2018). Pueblos mágicos: plan de desarrollo turístico de Pile con un enfoque de rescate cultural. Revista Turydes: Turismo y Desarrollo local sostenible 25. ISSN: 1988-5261.

Benavides Maldonado J. E., Largo Sánchez N. Z., Matailo Yaguana L. J., Luzuriaga Granda I. J. y Ludeña Eras G. (2019). Análisis de la cadena de valor del sombrero de paja toquilla en Manabí. Brazilian Applied Science Review. 3(3): 1665-1676. ISSN 2595-3621.

Bennett B. C., Alarcón R. y Cerón C. (1992). The Ethnobotany of Carludovica palmata Ruíz \& Pavón (Cyclanthaceae) in Amazonian Ecuador. Economic Botany 46 (3): 233-240.

Brummitt, N. (2013). Carludovica palmata. La Lista Roja de Especies Amenazadas de la UICN 2013: e.T44392681A44401274.https://dx.doi.org/10.2305/IUCN.UK.20132.RLTS.T44392681A44401274.Descargado el 09 de abril de 2020.

Egüez, A., Gaona, M. y Albán, A. (2019). Mapa geológico de la República del Ecuador. Escala 1: 1000000. Instituto de Investigación Geológico y Energético - IIGE, adscrito al Ministerio de Energía y Recursos Naturales No Renovables. Instituto Geográfico Militar. Autorización Nº IGM - 2017 - 004, registro N²019.

Govaerts R. (ed). For a full list of reviewers see: http://apps.kew.org/wcsp/compilersReviewers.do (2019). WCSP: World Checklist of Selected Plant Families (version Aug 2017). In: Species 2000 \& ITIS Catalogue of Life, 2019 Annual Checklist (Roskov Y., Ower G., Orrell T., Nicolson D., Bailly N., Kirk P.M., Bourgoin T., DeWalt R.E., Decock W., Nieukerken E. van, Zarucchi J., Penev L., eds.). Digital resource at www.catalogueoflife.org/annual-checklist/2019. Species 2000: Naturalis, Leiden, the Netherlands. ISSN 2405$884 X$.

Herrera, G.; Crespo, G.; Zambrano, D., y Cadena, P. (2014). Turismo y gestión: Una propuesta metodológica para la valoración y sistematización de atractivos turísticos en el cantón Rumiñahui. Revista Retos, 8(1) pp. 125-142.

Macías Mendoza, NV. (2019). Análisis de las influencias de la arquitectura vernácula de Pile (Manabí, Ecuador) en la producción artesana del tejido tradicional del sombrero de paja toquilla (Patrimonio Inmaterial de la Humanidad). Tesis de Máster Universitario en Conservación del Patrimonio Arquitectónico. Universidad Politécnica de Valencia. Disponible en http://hdl.handle.net/10251/131714

Méndez-Méndez A., Serrano de la Cruz Santos-Olmo M. A., Salinas Chávez, E., García-Romero A. 2018. Propuesta metodológica basada en indicadores para la valoración del potencial turístico del paisaje en áreas rurales: el 
Juan Francisco Villamar González, Luis David Zambrano Figueroa, Héctor Simón Pinargote Vélez

caso del municipio de Atlautla (México). Cuadernos de Turismo, 42: 335-354. ISSN: 1139-7861, eISSN: 19894635, doi: http://dx.doi.org/10.6018/turismo.42.15

Scolozzi R., U. Schirpke, C. Detassis, S. Abdullah y Gretter A. (2015) Mapping Alpine Landscape Values and Related Threats as Perceived by Tourists, Landscape Research, 40:4, 451-465, DOI: 10.1080/01426397.2014.902921

Stoffelen A. y Dominique V. (2015) An integrative geotourism approach: bridging conflicts in tourism landscape research, Tourism Geographies, 17:4, 544-560, DOI: 10.1080/14616688.2015.1053973

Vega-Almeida, R.L.; Fernández-Molina, J.C.; y Linares, R. (2009). Coordenadas paradigmáticas, históricas y epistemológicas de la Ciencia de la Información: una sistematización. Information Research, 14(2): 399.

Wee-Kheng T. y Tong-He C. (2012) El uso de fuentes de información turística en línea en la búsqueda de información turística: un estudio exploratorio, The Service Industries Journal, 32: 3, 451-476, DOI: 10.1080 / 02642069.2010.529130. 